\title{
Ultrasonographic evaluation of umbilical structures in Holstein calves: A comparison between healthy calves and calves affected by umbilical disorders
}

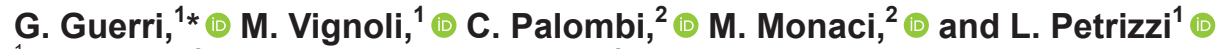 \\ ${ }^{1}$ Department of Veterinary Medicine, University of Teramo, Teramo 64100 Italy \\ ${ }^{2}$ Department of Veterinary Medicine, University of Perugia, Perugia 06126 Italy
}

\section{ABSTRACT}

The aim of this study was to evaluate, during the first $4 \mathrm{wk}$ of life, the involution of umbilical structures in clinically healthy calves and in calves affected by umbilical disorders, in both B-mode and color Doppler ultrasonography. The present study was carried out on 63 Holstein Friesian calves, divided into 3 different groups: group $\mathrm{H}$ (clinically healthy, $\mathrm{n}=17$ ), group $\mathrm{A}$, (affected by omphaloarteritis, $\mathrm{n}=24$ ), and group $\mathrm{V}$ (affected by omphalophlebitis, $\mathrm{n}=22$ ). B-mode ultrasonography was performed at weekly intervals, using a portable device (LOGIQ Book XP, GE Healthcare, Little Chalfont, UK) and a linear multifrequency 7 to $10 \mathrm{MHz}$ probe. In addition to the ultrasound examinations, the umbilicus of the calves was also evaluated using a color Doppler. The extra-abdominal as well as the intra-abdominal hemodynamics within the umbilical structures were evaluated using 3 different ranges of speed-flow detections $(23,14$, and $7 \mathrm{~cm} / \mathrm{s})$. In healthy calves, as the age increased, the umbilical structures decreased in size and their ultrasonographic identification became more difficult. Conversely, in affected calves the umbilical structures did not show the same progressive reduction of external diameters and areas, but had an irregular trend of regression. Also the color Doppler ultrasonography showed a significant difference in frequency and percentage of speed-flow in the early days of examination between the 3 groups, with the most reliable results detected from the umbilical arteries. In our experimental study, omphaloarteritis could be detected at the $\mathrm{d} 1$ color Doppler exam, with a $100 \%$ specificity and a $100 \%$ positive predictive value. Key words: calf, umbilical structure, ultrasound, color Doppler

Received April 3, 2019.

Accepted November 5, 2019.

*Corresponding author: guerri.giu@gmail.com
INTRODUCTION

Umbilical disorders represent the third most frequent cause of disease in young calves, after digestive and respiratory disorders, and generally occur in the period immediately after birth (Virtala et al., 1996a). These disorders are related to significant economic losses for farmers, leading to a substantial decrease in the ADG and overall BW, compared with healthy calves, caused by the chronic inflammatory response of this drawn-out condition (Virtala et al., 1996b). For the diagnosis of umbilical diseases localized within the external stump (omphalitis), palpation is the easiest and most important examination technique but has limitations for the diagnosis of umbilical infection of internal structures, such as urachitis, omphalophlebitis, and omphaloarteritis (Lischer and Steiner, 1994). Although most umbilical disorders are associated with a visible and palpable umbilical swelling, some do not cause external abnormalities (Staller et al., 1995). Furthermore, the exact extent of the disease and the involvement of other inner structures, such as the liver and the urinary bladder, can only be determined by means of an ultrasonographic examination (Lischer and Steiner, 1994). Within the past $20 \mathrm{yr}$, ultrasonography of umbilical structures has markedly gained importance as a diagnostic and prognostic aid when assessing calves suffering from umbilical disorders (Steiner and Lejeune, 2009).

Ultrasonography gives reliable aid not only for the diagnosis of umbilical diseases, but also for choosing the best treatment. Several umbilical disorders require surgical intervention (Rings, 1995; Mulon and Desrochers, 2005; Williams et al., 2014). Before surgery, a meticulous planning is essential, and ultrasonography can help in selecting the best surgical approach. Otherwise, in cases with poor prognosis, attempts at surgical repair can be put aside, also for economic reasons (Steiner and Lejeune, 2009).

The efficiency of ultrasonography in evaluating umbilical structures, and its agreement with physical 
postmortem findings has been proved (Staller et al., 1995; O'Brien and Forrest, 1996). Many other studies have investigated the ultrasonographic appearance of umbilical structures in clinically healthy calves, and have evaluated their involution during the first weeks of life (Lischer and Steiner, 1993; Watson et al., 1994; Bombardelli et al., 2018). Through a standardized ultrasonographic technique, these authors determined the size of the umbilical structures, establishing a range of normal values for these structures, that can be used as a reference for calves with suspected umbilical abnormalities. However, none of these studies have analyzed the hemodynamics of umbilical blood flow.

Color Doppler ultrasonographic examination of umbilical structures is widely used in human medicine (Sinkovskaya et al., 2013). In veterinary medicine, several studies have investigated fetal umbilical blood flow during pregnancy and during stage II of labor in dogs, horses, and cows (Bollwein et al., 2004; Di Salvo et al., 2006; Bleul et al., 2007; Waldvogel and Bleul, 2014), but to the best of our knowledge, it has never been used in calves for evaluating the involution of umbilical structures during first month of life.

The objective of this study is to evaluate the involution of the umbilical structures in clinically healthy calves and in calves affected by umbilical disorders during the first 4 wk of life, by ultrasonography, using the B-mode and color Doppler imaging techniques. To this aim, both extraabdominal and intraabdominal umbilical structures were assessed by B-mode ultrasonographic examination, and color Doppler analysis using 3 different range of speed-flow detections. The purpose was to evaluate the availability of color Doppler imaging technique to investigate umbilical disorders in calves, and to compare the results with those assessed by B-mode ultrasonographic examination.

\section{MATERIALS AND METHODS}

The present study was part of a large study on Holstein Friesian cows, approved by the local ethical committee "Interuniversity Ethics Committee for Animal Research" (number 41/2012/CEISA). The study was carried out on Holstein Friesian calves born on dairy farms selected by the Faculties of Veterinary Medicine of Teramo and Perugia, between March 2013 and April 2017.

Within $24 \mathrm{~h}$ of birth, every newborn calf underwent a clinical and ultrasonographic evaluation of the umbilical stump and remnants. All scans in d 1 were performed between h 10 and 22 after birth, except 3 calves in which the examination was performed in the second hour after birth. Subsequent scans were performed at weekly intervals until 4 wk of age.
Clinical examination consisted in a general assessment followed by a thorough evaluation of the umbilical stump, considering any change on inspection or palpation, such as heat or increase in size and changes in consistency. Deep abdominal palpation was performed to evaluate if the intra-abdominal umbilical structures were affected. Calves that were markedly ill, with mild to severe signs of respiratory, digestive, nervous, or other septicemic diseases, were excluded from the study.

For the ultrasonographic examination of the umbilical stump and umbilical remnants, the hair was clipped over the skin of the ventral aspect of the abdomen, between the inguinal region and the xiphoid. An adequate amount of coupling gel was applied to accurately image the structures. Ultrasonography was performed by the same operator using a portable device (LOGIQ Book XP, GE Healthcare, Little Chalfont, UK), and a linear multifrequency probe 7 to $10 \mathrm{MHz}$, without a standoff pad. The B-mode examination was performed with the calf in left lateral recumbency while manually restraining it. The examination started with the evaluation of the 2 umbilical arteries and the urachus, followed by the evaluation of the extraabdominal umbilical structures and the umbilical vein. Umbilical arteries were assessed with the probe positioned at the midpoint of the urinary bladder, in the transverse plane, to the left and to the right of the urinary bladder. Here, the measurements were performed. The area of each artery was calculated and their diameters were measured transversely (horizontally) and from dorsal to ventral (vertically), obtaining long and short diameter, because umbilical arteries are not perfectly circular in transverse section. A longitudinal section of the apex of the bladder was visualized to assess the possible presence of urachal remnants. Extraabdominal umbilical structures were assessed with the probe positioned on the cranial edge of the umbilical stump, transverse to the long axis of the cord. Measurements of the external diameter of the stump were made from margins underlying the skin surface. The umbilical vein was assessed throughout its course. Similar to umbilical arteries, the umbilical vein is not perfectly circular in transverse section; thus, its diameters were measured both horizontally and vertically, obtaining long and short diameter. Measurements of area and diameters were obtained in 4 different segments inside the body wall: the first (A) was close to the umbilical stump, immediately cranial to the inner umbilical ring, the second (B) was at the midpoint between the liver and the abdominal wall, the third (C) constituted the point just before the liver, and the fourth (D) represented the entrance of the vein within the liver (Figure 1).

After B-mode ultrasonographic examination, the newborn underwent a color Doppler ultrasonographic 
examination to evaluate flow of both the extraabdominal and the intraabdominal vascular umbilical structures, with 3 different range of speed-flow detections. To obtain the most accurate range of speed-flow for each type of vessel, on every examination each section of the umbilical vessel was evaluated using a range of speed-flow detection of 23,14 , and $7 \mathrm{~cm} / \mathrm{s}$.

Mean and standard deviation for each measured structure were calculated through SPSS software (IBM SPSS Statistics 22, IBM Corp., Armonk, NY) using the Mann-Whitney U test, with a $P$-value $\leq 0.05$. Frequency and percentage of different speed-flows were measured. Sensitivity, specificity, positive predictive value (PPV), and negative predictive value (NPV) of color Doppler ultrasonographic examination were calculated.

On the basis of clinical and B-mode ultrasonographic evaluation of the umbilical stump and remnants, each calf was allocated to 1 of 3 different groups: group $\mathbf{H}$, including clinically healthy newborns (no signs of pain on palpation, no heat or increase in size or firmness of the stump, no hyperthermia), and no ultrasonographic evidence of umbilical involvement; group $\mathbf{A}$, including newborns clinically affected by omphaloarteritis (palpation of hard tubular structures that move caudally from the umbilical stump, pain on deep abdominal palpation, hyperthermia, swelling of the stump, urinary disorders), and with ultrasonographic signs of infection [presence of hyperechogenic material inside the arterial lumen or surrounding the arteries, diameter exceeding the normal range (Watson et al., 1994), thickening of the arterial wall]; and group $\mathbf{V}$, including newborns clinically affected by omphalophlebitis (palpation of an hard tubular structure which can be followed cranially from the umbilical stump, pain on ventral abdominal palpation, heat or increase in size or firmness of the stump, purulent drainage, hyperthermia), with ul-
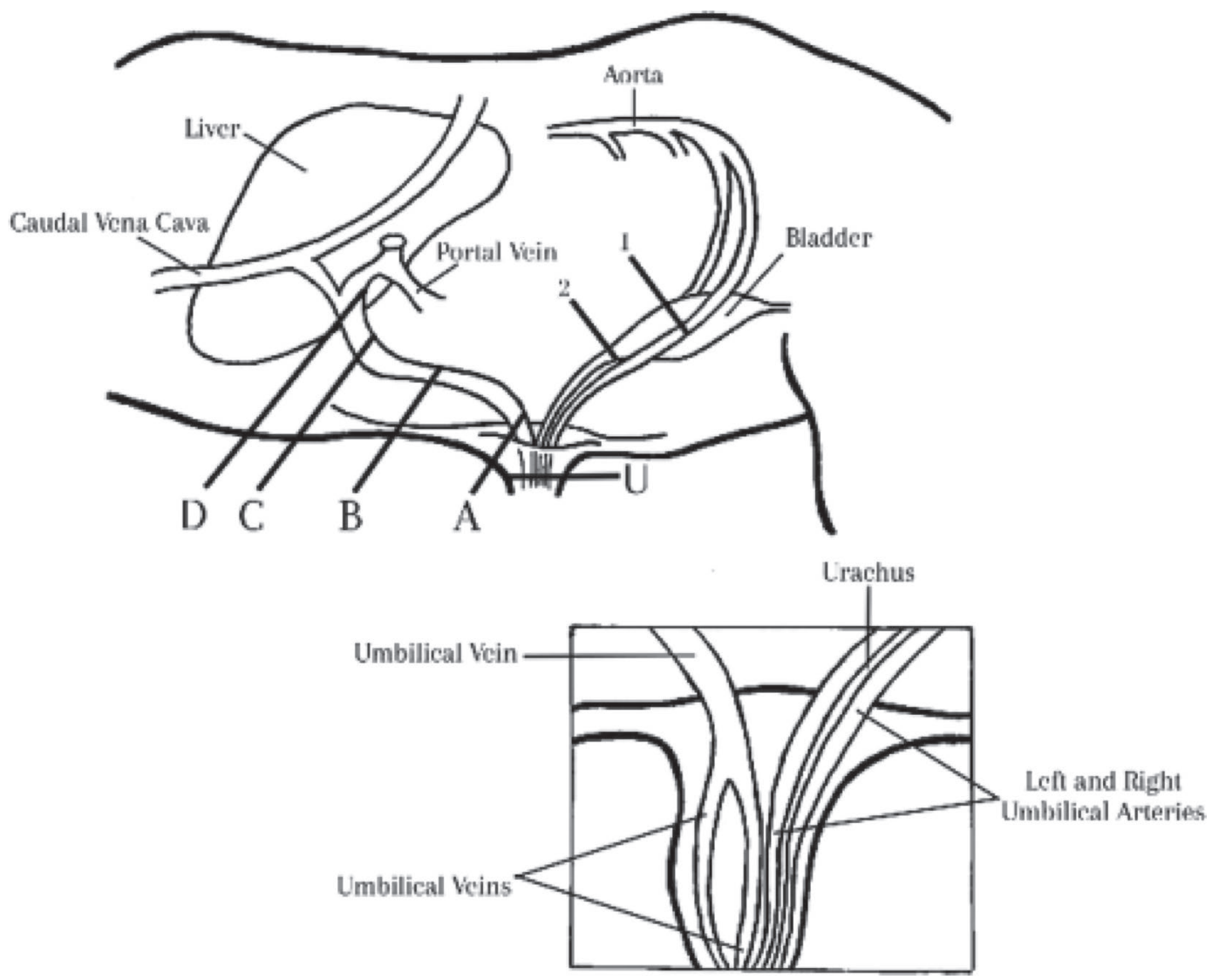

Figure 1. Diagram of the umbilical structures in the calf and transducer position for scanning. Umbilical arteries were assessed with the probe positioned at the midpoint of the urinary bladder (1). A longitudinal section of the apex of the bladder was performed to assess the possible presence of urachal remnants (2). Extraabdominal umbilical structures were assessed with the probe positioned on the cranial edge of the umbilical stump, transversely to the long axis of the cord $(\mathrm{U})$. The umbilical vein was assessed throughout its course and measurements were obtained in 4 different segments inside the body wall: the first (A) was close to the umbilical stump, immediately cranial to the inner umbilical ring, the second (B) was at midpoint between the liver and the abdominal wall, the third (C) constituted the point just before the liver, and the fourth (D) represented the entrance of the vein within the liver. 
trasonographic evidence of infection, formation of an abscess, or both [presence of hyperechogenic material inside the venous lumen or surrounding the veins, diameters exceeding the normal range (Watson et al., 1994), thickening of the venous wall, lumen not completely anechoic, presence of granular hyperechogenic material within a defined cavity along the course of the veins, inside the hepatic parenchyma, or both]. After the subsequent ultrasonographic examinations, the calf was either confirmed in its group or assigned to the correct group, in cases of previous error.

\section{RESULTS}

The present study was carried out on 63 Holstein Friesian calves. On the basis of clinical and ultrasonographic evaluation of the umbilical stump and remnants, 17 clinically healthy newborn calves were included in group H, 24 newborns affected by omphaloarteritis were included in group A, and 22 newborns affected by omphalophlebitis were included in group V. To simplify the presentation of the results, all data with statistical significance (i.e., level of significance at $P$-value $\leq 0.05)$ are shown in tables.

\section{Group H}

None of the 17 calves showed signs of umbilical diseases: no anomalies in consistency or heat during the palpation and no hyperthermia were evident. Within 3 to $4 \mathrm{~d}$ after birth, the stump was dry and after about 2 wk it fell off.

Umbilical Arteries and Urachus. Each umbilical artery was identified lateral to the urinary bladder and could be followed only a few centimeters cranial to the bladder apex. On d 1 scan, they appeared as circular structures, with a hypoechoic wall, surrounded by an anechoic ring (Figure 2). A decrease occurred in the diameter of umbilical arteries from d 1 to 28 .

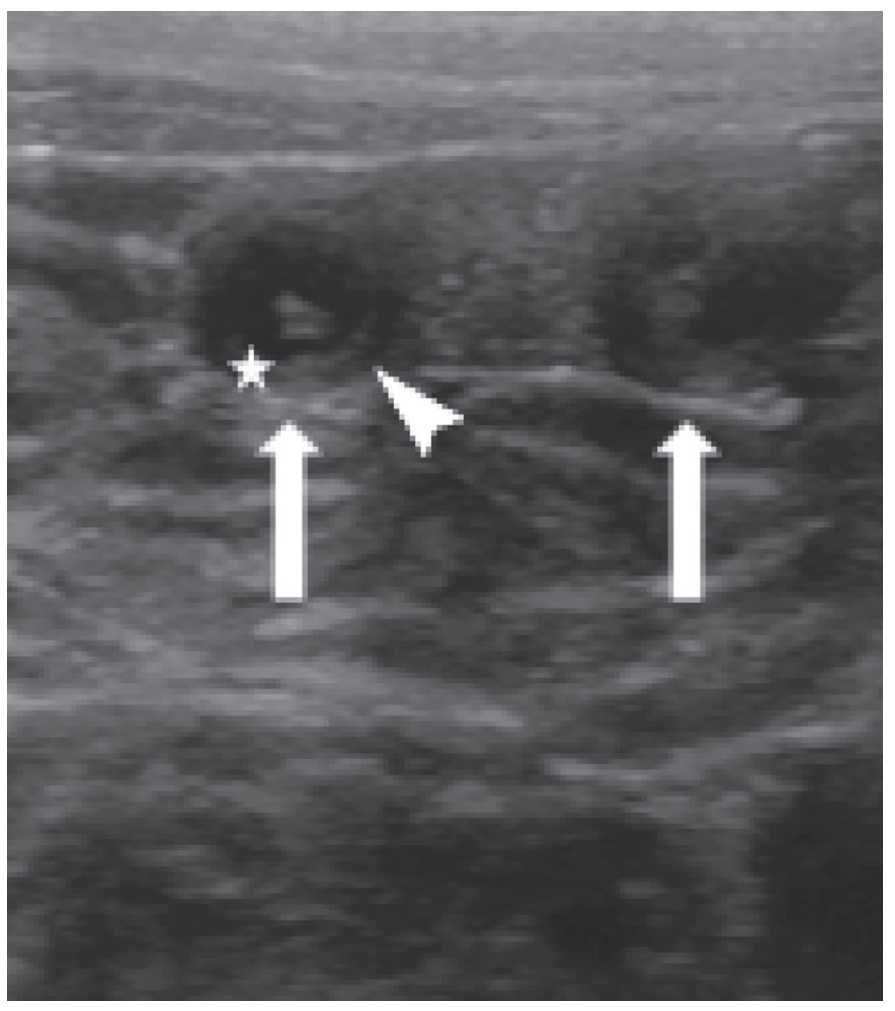

Figure 2. Transverse image of umbilical arteries in clinically healthy calves (group $\mathrm{H}$ ) on d 1 scan. The 2 umbilical arteries (arrows) appear as circular structures, with a hypoechoic wall (star), surrounded by an anechoic ring (arrowhead).

Table 1 highlights the mean diameter and mean area of the umbilical arteries over time from birth until 4 wk postpartum. Urachal tissue was not detected in any of the calves.

Umbilical Stump. The umbilical stump was oval in cross section and the umbilical tissue appeared with a homogeneously hypoechoic pattern, similar in echogenicity to the surrounding tissue, from which it was separated, in all the calves on 11 scan, by an anechoic

Table 1. Mean diameter $(\mathrm{cm})$ and area $\left(\mathrm{mm}^{2}\right)$ of umbilical arteries in clinically healthy calves (group H) over time from birth until 4 wk postpartum (results presented as mean value $\pm \mathrm{SD})^{1}$

\begin{tabular}{|c|c|c|c|c|c|c|}
\hline Age (d) & \multicolumn{3}{|c|}{ Right artery } & \multicolumn{3}{|c|}{ Left artery } \\
\hline 7 & $0.88 \pm 0.16$ & $0.75 \pm 0.15$ & $56.15 \pm 20.07$ & $0.81 \pm 0.14 \dagger$ & $0.74 \pm 0.13$ & $51.44 \pm 17.76^{* *}$ \\
\hline 14 & $0.78 \pm 0.19^{*}$ & $0.66 \pm 0.20^{*}$ & $48.06 \pm 22.87^{*}$ & $0.71 \pm 0.15 \dagger$ & $0.65 \pm 0.10$ & $38.33 \pm 16.95^{*}$ \\
\hline 21 & $0.61 \pm 0.19^{* *}$ & $0.49 \pm 0.12^{* *}$ & $29.00 \pm 17.69^{* *}$ & $0.60 \pm 0.08^{*}$ & $0.52 \pm 0.12^{*}$ & $28.67 \pm 13.13^{*}$ \\
\hline 28 & $0.56 \pm 0.13^{*}$ & $0.45 \pm 0.16^{*}$ & $26.16 \pm 13.77^{* *}$ & $0.55 \pm 0.06^{* *}$ & $0.46 \pm 0.10^{* *}$ & $26.05 \pm 7.80^{* *}$ \\
\hline
\end{tabular}

${ }^{1}$ Measures of the umbilical arteries were obtained at the midpoint of the urinary bladder. The area of each artery was calculated and their diameters were measured transversely (horizontally) and from dorsal to ventral (vertically), obtaining long and short diameter.

$\dagger P<0.10 ;{ }^{*} P<0.05 ;{ }^{*} P<0.01$. 


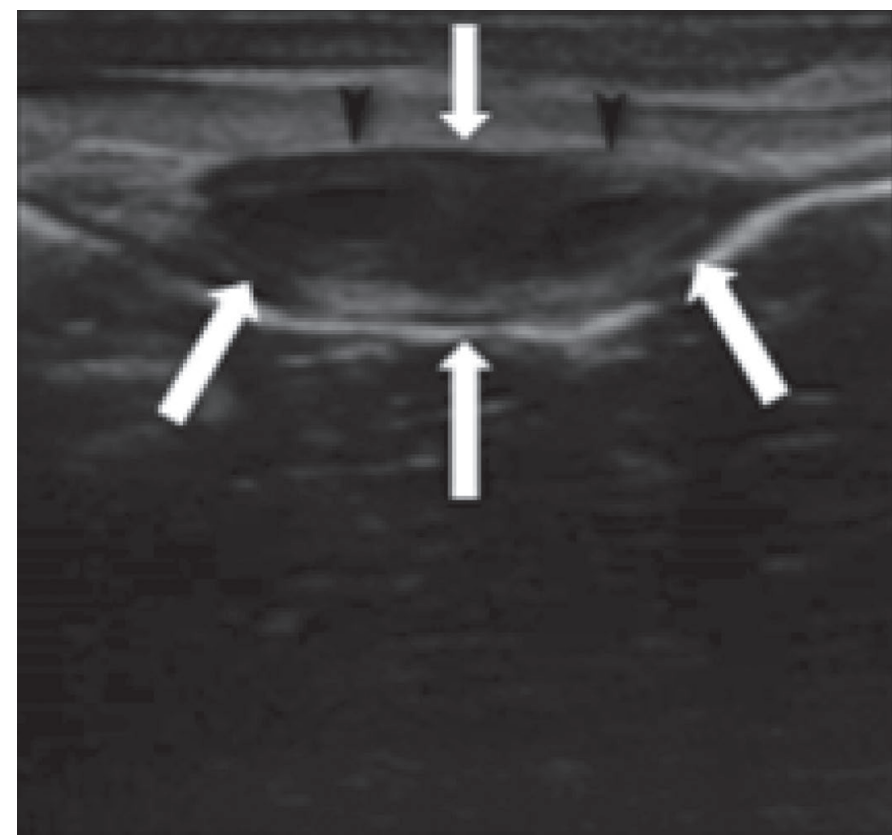

Figure 3. Transverse image of umbilical stump in clinically healthy calves (group $\mathrm{H}$ ) on $\mathrm{d} 7$. The umbilical tissue appears with a homogeneously hypoechoic pattern, similar in echogenicity to the surrounding tissue, from which it is separated by an anechoic border (arrows). The 2 oval structures, with an anechoic lumen and a hypoechoic wall (arrow heads), are umbilical veins.

border (Figure 3). The umbilical veins appeared as round or oval structures, with an anechoic lumen and a hypoechoic wall. Neither the umbilical arteries nor the urachus were detected within the umbilical stump. Table 2 shows the mean diameter of the umbilical stump over time from birth to 4 wk postpartum.

Umbilical Vein. The umbilical vein was followed from the cranial edge of the umbilical stump to the liver, where it joined the left branch of the portal vein. In every calf, throughout its intra-abdominal course, the vein appeared as an oval or round structure, with a defined hypoechoic wall, an anechoic lumen, and a hyperechoic border between the wall and the lumen

Table 2. Mean diameter $(\mathrm{cm})$ of umbilical stump in clinically healthy calves (group H) over time from birth until 4 wk postpartum (results presented as mean value $\pm \mathrm{SD})^{1}$

\begin{tabular}{lll}
\hline Age $(\mathrm{d})$ & Long diameter & Short diameter \\
\hline 1 & $2.72 \pm 0.40 \dagger$ & $1.06 \pm 0.18 \dagger$ \\
7 & $2.21 \pm 0.39$ & $0.81 \pm 0.29$ \\
14 & $1.92 \pm 0.26^{*}$ & $0.68 \pm 0.22 \dagger$ \\
21 & $1.77 \pm 0.29^{* *}$ & $0.56 \pm 0.19^{*}$ \\
28 & $1.62 \pm 0.25^{* *}$ & $0.49 \pm 0.18^{*}$ \\
\hline
\end{tabular}

${ }^{1}$ Measures of the external diameter of the stump were made from margins underlying the skin surface.

$\dagger P<0.10 .{ }^{*} P<0.05 .{ }^{* *} P<0.01$.

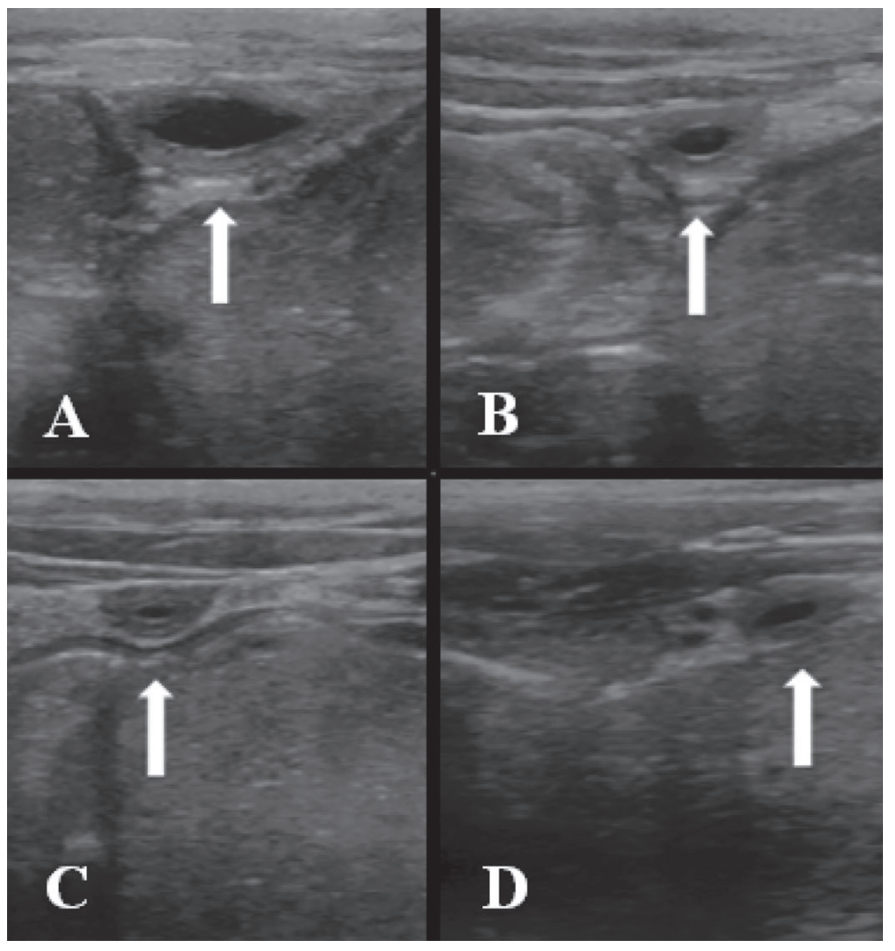

Figure 4. Transverse image of umbilical vein in clinically healthy calves (group $\mathrm{H}$ ) on $\mathrm{d} 1$ scan. $\mathrm{A}=$ umbilical vein in segment $\mathrm{A}$; $\mathrm{B}$ $=$ umbilical vein in segment $\mathrm{B} ; \mathrm{C}=$ umbilical vein in segment $\mathrm{C} ; \mathrm{D}$ $=$ umbilical vein in segment $\mathrm{D}$. The vein (arrows), throughout its intra-abdominal course, appears as an oval or round structure, with a defined hypoechoic to the surrounding tissue wall, an anechoic lumen and a hyperechoic border between the wall and the lumen.

(Figure 4). The diameters and the areas of the veins became smaller toward the liver and increased again within the liver. The diameter of the umbilical veins decreased from $\mathrm{d} 1$ to 28 . Table 3 shows the mean diameter and mean area of the umbilical vein over time from birth to 4 wk postpartum.

Color Doppler. In healthy calves blood flow was never detected at any segment of the umbilical arteries, umbilical stump, or vein in segment $\mathrm{A}$, at any time after birth. A positive color Doppler was detected in segment B of the vein on $\mathrm{d} 1$, at 7 and $14 \mathrm{~cm} / \mathrm{s}$ velocity range, in only 2 calves. On $\mathrm{d} 1$ a positive color Doppler was observed in segment $\mathrm{C}$ of the vein in 3 calves at the 7 and $14 \mathrm{~cm} / \mathrm{s}$ velocity range, and in 1 calf at $23 \mathrm{~cm} / \mathrm{s}$. Positive color Doppler in segment D of the umbilical vein was detected in 4 calves at the $7 \mathrm{~cm} / \mathrm{s}$ velocity range, and in 1 calf at 14 and $23 \mathrm{~cm} / \mathrm{s}$. In the group of healthy calves, blood flow in segments B, C, and $\mathrm{D}$ of the umbilical vein was never detected after $\mathrm{d}$ 1 examination.

Positive color Doppler results in the umbilical vessels in the healthy group (group H) at $\mathrm{d} 1$ and 7 are shown in Table 4. 


\section{Group A}

Twenty-four calves were included in this group. Five calves died $7 \mathrm{~d}$ after birth and 1 calf $14 \mathrm{~d}$ after. Bilateral omphaloarteritis was diagnosed in 17 calves, whereas a single umbilical artery was affected in 7 calves: 5 calves had an infection of the right artery and 2 calves of the left artery.

Umbilical Arteries. The arteries appeared as circular structures, with a hypoechoic wall and a heterogeneous lumen (Figure 5). Because of the presence of hyperechoic purulent material, it was difficult to clearly recognize the borders of the arterial wall in some calves. Table 5 shows the mean diameter and mean area of the umbilical arteries over time from birth until $4 \mathrm{wk}$ postpartum.

Color Doppler. In calves affected by omphaloarteritis, blood flow was detected at $\mathrm{d} 1$ with every range of speed. In the right artery, 6 calves had a positive color Doppler at the $7 \mathrm{~cm} / \mathrm{s}$ velocity range, 5 calves at $14 \mathrm{~cm} / \mathrm{s}$, and 3 calves at $23 \mathrm{~cm} / \mathrm{s}$. In the left artery, the color Doppler detection was positive in 6 calves at $7 \mathrm{~cm} / \mathrm{s}$ velocity range, in 4 calves at $14 \mathrm{~cm} / \mathrm{s}$, and in 2 calves at $23 \mathrm{~cm} / \mathrm{s}$. In calves affected by omphaloarteritis, blood flow was never detected after the $\mathrm{d} 1$ examination.

The positive color Doppler results in the umbilical arteries of calves affected by omphaloarteritis (group A) at $\mathrm{d} 1$ are shown in Table 6 .

\section{Group V}

Twenty-two calves were included in this group. Six calves died $3 \mathrm{~d}$ after birth, 1 calf $7 \mathrm{~d}$ after, 1 calf 14 $\mathrm{d}$ after, and another calf $21 \mathrm{~d}$ after birth. The vein was affected throughout its intra-abdominal course in 14 calves. In 8 calves the vein was affected only in segment A and B. Involvement of the umbilical stump (omphalitis) was detected in 9 calves. Ten days after birth, a secondary hernia occurred in a calf with an omphalophlebitis localized in segments A and B. None of the calves showed involvement of the liver.

Umbilical Vein. The umbilical vein was followed from the umbilical stump to the liver where it joined the left branch of the portal vein. Throughout the intra-abdominal course, the vein appeared as an oval or round structure, with a definite thickened hypoechoic wall (Figure 6). In some calves purulent material was present inside the umbilical stump and it was not possible to clearly identify the venous wall. Table 7 shows the mean diameter of the umbilical stump over time from birth to $4 \mathrm{wk}$ postpartum. The diameter and the area of the umbilical vein are summarized in Table 8 . 
Table 4. Positive color Doppler results in the umbilical vessels in clinically healthy calves (group H) at d 1 and $7^{1}$

\begin{tabular}{|c|c|c|c|c|c|c|}
\hline \multirow[b]{2}{*}{ Group H } & \multicolumn{3}{|c|}{ d 1} & \multicolumn{3}{|c|}{ d 7} \\
\hline & CF 7 & CF 14 & CF 23 & CF 7 & CF 14 & CF 23 \\
\hline \multicolumn{7}{|l|}{ Right artery } \\
\hline \multicolumn{7}{|l|}{ Left artery } \\
\hline \multicolumn{7}{|l|}{ Umbilical stump } \\
\hline \multicolumn{7}{|l|}{ Vein segment A } \\
\hline Vein segment B & $11(2 / 17)$ & $11(2 / 17)$ & & & & \\
\hline Vein segment C & $17(3 / 17)$ & $17(3 / 17)$ & $5(1 / 17)$ & & & \\
\hline Vein segment D & $23(4 / 17)$ & $5(1 / 17)$ & $5(1 / 17)$ & & & \\
\hline
\end{tabular}

${ }^{1}$ Results are presented as percentages of positive color Doppler detection, followed parenthetically by number of calves positive at Doppler examination. CF $7=$ color Doppler at $7 \mathrm{~cm} / \mathrm{s}$ velocity range. $\mathrm{CF} 14=$ color Doppler at $14 \mathrm{~cm} / \mathrm{s}$ velocity range. $\mathrm{CF} 23=$ color Doppler at $23 \mathrm{~cm} / \mathrm{s}$ velocity range.

Color Doppler. After birth, in the calves affected by omphalophlebitis, the blood flow in the umbilical stump was never detected at any velocity range or at any time. On the d 1 examination, in segments A, B, C, and D of the vein, a positive color Doppler was detected in 27 , 31,36 , and $50 \%$ of calves, respectively, using a velocity range of $7 \mathrm{~cm} / \mathrm{s}$. A positive color Doppler was detected in the 13,9 , and $31 \%$ of calves, in segments A-B, C, and $\mathrm{D}$, respectively, using a velocity range of $14 \mathrm{~cm} / \mathrm{s}$, and in $4.5,9$, and $13 \%$ of calves, in segments B, C, and $\mathrm{D}$, respectively, at the $23 \mathrm{~cm} / \mathrm{s}$ velocity range. On the d 7 examination, 1 calf had a positive color Doppler in segment B, 2 calves in segment $\mathrm{C}$ and $\mathrm{D}$, at the $7 \mathrm{~cm} / \mathrm{s}$ velocity range; 1 calf was positive in segments $\mathrm{C}$ and $\mathrm{D}$ at $14 \mathrm{~cm} / \mathrm{s}$, and 1 calf in segment D at $23 \mathrm{~cm} / \mathrm{s}$. After the $\mathrm{d} 7$ examination, no more blood flow was detected in the calves affected by omphalophlebitis.

The positive color Doppler results of the umbilical veins in the calves affected by omphalophlebitis (group V) at $d 1$ and 7 are shown in Table 9 .

\section{DISCUSSION}

The results of this study indicate that the ultrasonography is an excellent technique for the examination of the umbilical structures in healthy calves and in calves affected by umbilical diseases, and for evaluating their adequate involution. Through a standardized technique, a range of normal and pathological values for the umbilical stump, umbilical arteries, umbilical

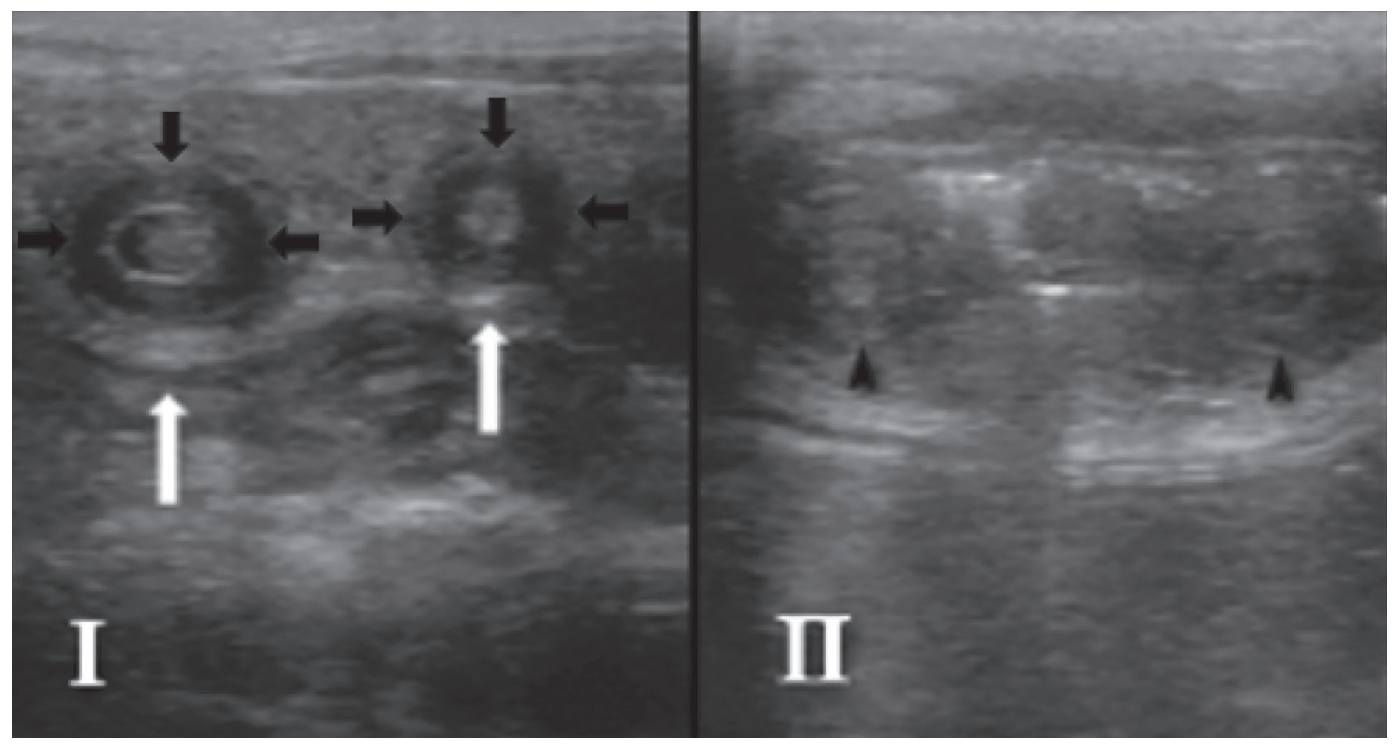

Figure 5. Transverse image of umbilical arteries in calves affected by omphaloarteritis (group A). (I) The arteries (white arrows) appear as circular structures, with a hypoechoic wall (black arrows) and a heterogeneous lumen. (II) Because of the presence of hyperechoic purulent material, it is difficult to clearly recognize the limits of the arterial wall (arrowheads). 
Table 5. Mean diameter $(\mathrm{cm})$ and area $\left(\mathrm{mm}^{2}\right)$ of umbilical arteries in calves affected by omphaloarteritis (group A) over time from birth until 4 wk postpartum (results presented as mean value $\pm \mathrm{SD})^{1}$

\begin{tabular}{|c|c|c|c|c|c|c|}
\hline Age (d) & \multicolumn{3}{|c|}{ Right artery } & \multicolumn{3}{|c|}{ Left artery } \\
\hline 14 & $0.91 \pm 0.25^{*}$ & $0.78 \pm 0.21^{*}$ & $64.84 \pm 33.42^{*}$ & $0.85 \pm 0.25 \dagger$ & $0.71 \pm 0.18$ & $58.18 \pm 27.15^{*}$ \\
\hline 21 & $0.87 \pm 0.18^{* *}$ & $0.79 \pm 0.19^{* *}$ & $60.99 \pm 27.91^{* *}$ & $0.92 \pm 0.26^{*}$ & $0.81 \pm 0.26^{*}$ & $68.30 \pm 38.25^{*}$ \\
\hline 28 & $0.76 \pm 0.16^{*}$ & $0.63 \pm 0.15^{*}$ & $46.24 \pm 17.18^{* *}$ & $0.74 \pm 0.09^{* *}$ & $0.66 \pm 0.09^{* *}$ & $44.50 \pm 13.11^{* *}$ \\
\hline
\end{tabular}

${ }^{1}$ Measures of the umbilical arteries were obtained at the midpoint of the urinary bladder. The area of each artery was calculated and their diameters were measured transversely (horizontally) and from dorsal to ventral (vertically), obtaining long and short diameter.

$\dagger P<0.10 .{ }^{*} P<0.05$. ${ }^{* *} P<0.01$.

veins, and urachus can be established; these values can be a reference for evaluating calves with suspected umbilical abnormalities.

The umbilical cord represents the connection in uterus between the dam and the fetus (Rings, 1995). The umbilical involution should proceed as rapidly as possible, but often it is delayed and abnormal, because of exposure of the amnion sheath and navel stump to contaminations from the environment representing a potential route of entry for the pathogens (Lischer and Steiner, 1994). An umbilical infection may be seen as a localized infection within the external stump (omphalitis), or an infection of the internal structures (urachitis, omphalophlebitis, omphaloarteritis, omphalovasculitis, and panvasculitis). Arcanobacterium pyogenes and Escherichia coli are considered the most common causes of umbilical remnant infections in calves (Baxter, 1989). Ultrasonographic examination represents an ideal diagnostic tool in visualizing the external and the

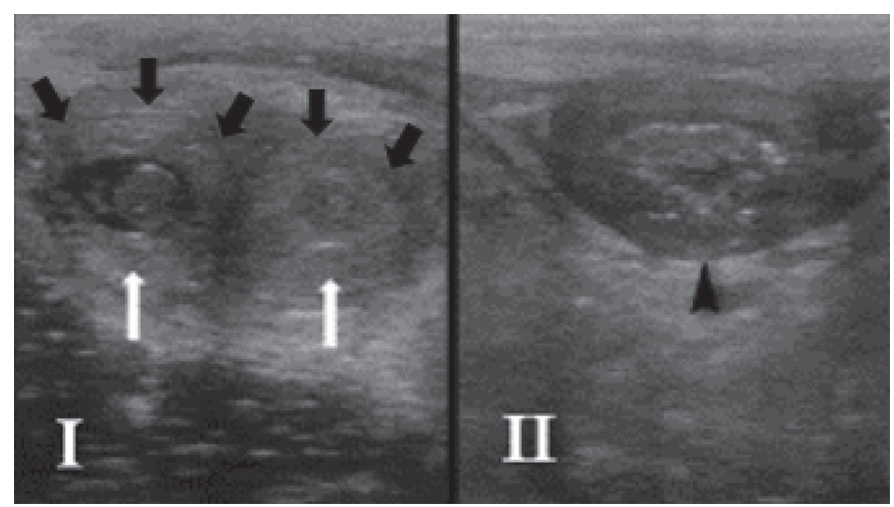

Figure 6. Transverse image of umbilical veins inside umbilical stump in calves affected by omphalophlebitis (group V). (I) The umbilical veins (white arrows) appear as oval or round structures, with a definite thickened hypoechoic wall (black arrows). (II) Because of the presence of purulent material inside the umbilical stump (arrow head), it is not possible to clearly identify the venous wall of both umbilical veins. internal umbilical structures and could help localize the infection.

In this study the ultrasonographic examination was performed on a manually restrained calf in left lateral recumbency, without sedation.

In healthy calves (group $\mathrm{H}$ ), the umbilical stump was oval in shape and decreased in size from $1 \mathrm{~d}$ to $4 \mathrm{wk}$ of age, as reported by Watson et al. (1994), passing from having a mean diameter of $2.72 \times 1.06 \mathrm{~cm}$ at $1 \mathrm{~d}$, to $1.62 \times 0.49 \mathrm{~cm}$ at $28 \mathrm{~d}$. It appeared as a hypoechoic tissue, similar in echogenicity to the surrounding tissue, with an anechoic border hardly detectable after 4 wk. Inside the stump, the 2 umbilical veins were best imaged during the first week of life. After the second week of life, their dimension regressed substantially and it became more difficult to clearly identify the wall because of the similar echogenicity with the surrounding umbilical tissue. Conversely, calves affected by omphalophlebitis (group V), showed only a moderate and irregular reduction in size both of the umbilical stump and the umbilical veins, and it was not possible to clearly identify the wall of the veins inside the umbilical stump in some calves because of the presence of purulent material.

In healthy calves (group $\mathrm{H}$ ), the umbilical arteries were clearly identified during the first 4 wk of life on the lateral aspects of the urinary bladder, in agreement with previous studies (Lischer and Steiner, 1993; Watson et al., 1994). After birth, the blood in the umbilical arteries coagulates, so that after a few days of life, the vessels no longer appeared anechoic but heterogeneously hyperechoic. Then umbilical arteries decreased their size from d 1 to $4 \mathrm{wk}$ of age, passing from a mean diameter of $0.91 \times 0.78 \mathrm{~cm}$ for the right artery and 0.98 $\times 0.80 \mathrm{~cm}$ for the left artery at $1 \mathrm{~d}$, to $0.56 \times 0.45 \mathrm{~cm}$ and $0.55 \times 0.46 \mathrm{~cm}$ at $28 \mathrm{~d}$, respectively. Conversely, in calves affected by omphaloarteritis (group A), the umbilical arteries did not progressively decrease their external diameters and areas. Both umbilical arteries, 
Table 6. Positive color Doppler results in the umbilical arteries in calves affected by omphaloarteritis (group A) at $\mathrm{d} 1^{1}$

\begin{tabular}{lccl}
\hline & \multicolumn{3}{c}{$\mathrm{d} 1$} \\
\cline { 2 - 4 } Group A & CF 7 & CF 14 & CF 23 \\
\hline Right artery & $25(6 / 24)$ & $20(5 / 24)$ & $12(3 / 24)$ \\
$\%$ & 0.25 & 0.20 & 0.12 \\
Sens & 1 & 1 & 1 \\
Spec & 1 & 1 & 1 \\
PPV & 0.48 & 0.47 & 0.44 \\
NPV & 0.56 & 0.55 & 0.48 \\
Acc & & & $8(2 / 24)$ \\
Left artery & $25(6 / 24)$ & $16(4 / 24)$ & 0.08 \\
\% & 0.25 & 0.16 & 1 \\
Sens & 1 & 1 & 1 \\
Spec & 1 & 1 & 0.43 \\
PPV & 0.48 & 0.45 & 0.46 \\
NPV & 0.56 & 0.51 & \\
Acc & & &
\end{tabular}

${ }^{1}$ Results are presented as percentages of positive color Doppler detection, followed parenthetically by number of calves positive at Doppler examination. Sens $=$ sensitivity; $\mathrm{Spec}=$ specificity; $\mathrm{PPV}=$ positive predictive value; NPV $=$ negative predictive value; $A c c=$ accuracy. Arteries were assessed to the lateral side of the urinary bladder. CF 7 $=$ color Doppler at $7 \mathrm{~cm} / \mathrm{s}$ velocity range. $\mathrm{CF} 14=$ color Doppler at 14 $\mathrm{cm} / \mathrm{s}$ velocity range. $\mathrm{CF} 23=$ color Doppler at $23 \mathrm{~cm} / \mathrm{s}$ velocity range.

indeed, had an irregular trend of regression, with an initial decrease of their dimensions, followed by an increase.

The umbilical vein was imaged from the base of the umbilical stump to the left branch of the portal vein in the liver. In healthy calves (group H), it was best imaged during the first week of life and it regressed in diameter and area toward the liver and increased within the liver (section D), as previously described by Lischer and Steiner (1993). The blood in the umbilical vein coagulates more slowly than in the umbilical arteries, and after $3 \mathrm{wk}$, the lumen no longer appeared anechoic, but heterogeneously hyperechoic. After the second week of age, the wall was barely distinguishable from the surrounding tissues and the umbilical vein dimensions were substantially decreased, rendering the visualization more difficult. However, this did not happen in calves affected by omphalophlebitis (group

Table 7. Mean diameter $(\mathrm{cm})$ of umbilical stump in calves affected by omphalophlebitis (group V) over time from birth until 4 wk postpartum (results presented as mean value $\pm \mathrm{SD})^{1}$

\begin{tabular}{lll}
\hline Age $(\mathrm{d})$ & Long diameter & Short diameter \\
\hline 1 & $2.52 \pm 0.36 \dagger$ & $0.99 \pm 0.26 \dagger$ \\
7 & $2.41 \pm 0.63$ & $1.00 \pm 0.43$ \\
14 & $2.27 \pm 0.57^{*}$ & $0.93 \pm 0.44 \dagger$ \\
21 & $2.11 \pm 0.31^{* *}$ & $0.80 \pm 0.38^{*}$ \\
28 & $1.94 \pm 0.33^{* *}$ & $0.57 \pm 0.16^{*}$ \\
\hline
\end{tabular}

${ }^{1}$ Measures of the external diameter of the stump were made from margins underlying the skin surface.

$\dagger P<0.10$. ${ }^{*} P<0.05$. ${ }^{* *} P<0.01$.

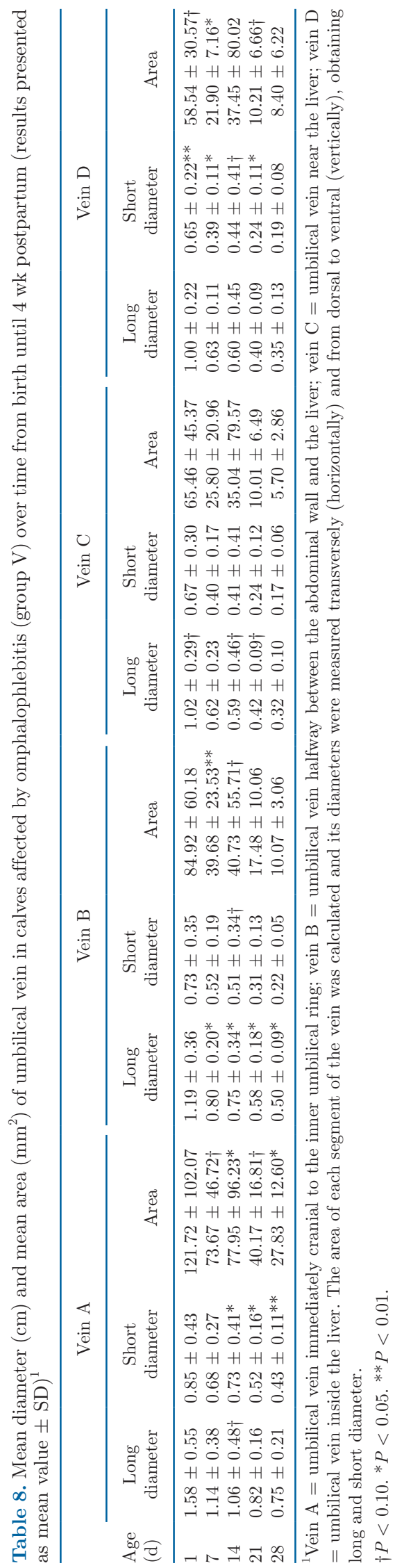

Journal of Dairy Science Vol. 103 No. 3, 2020 
Table 9. Positive color Doppler results in the umbilical veins in calves affected by omphalophlebitis (group V) at d 1 and $7^{1}$

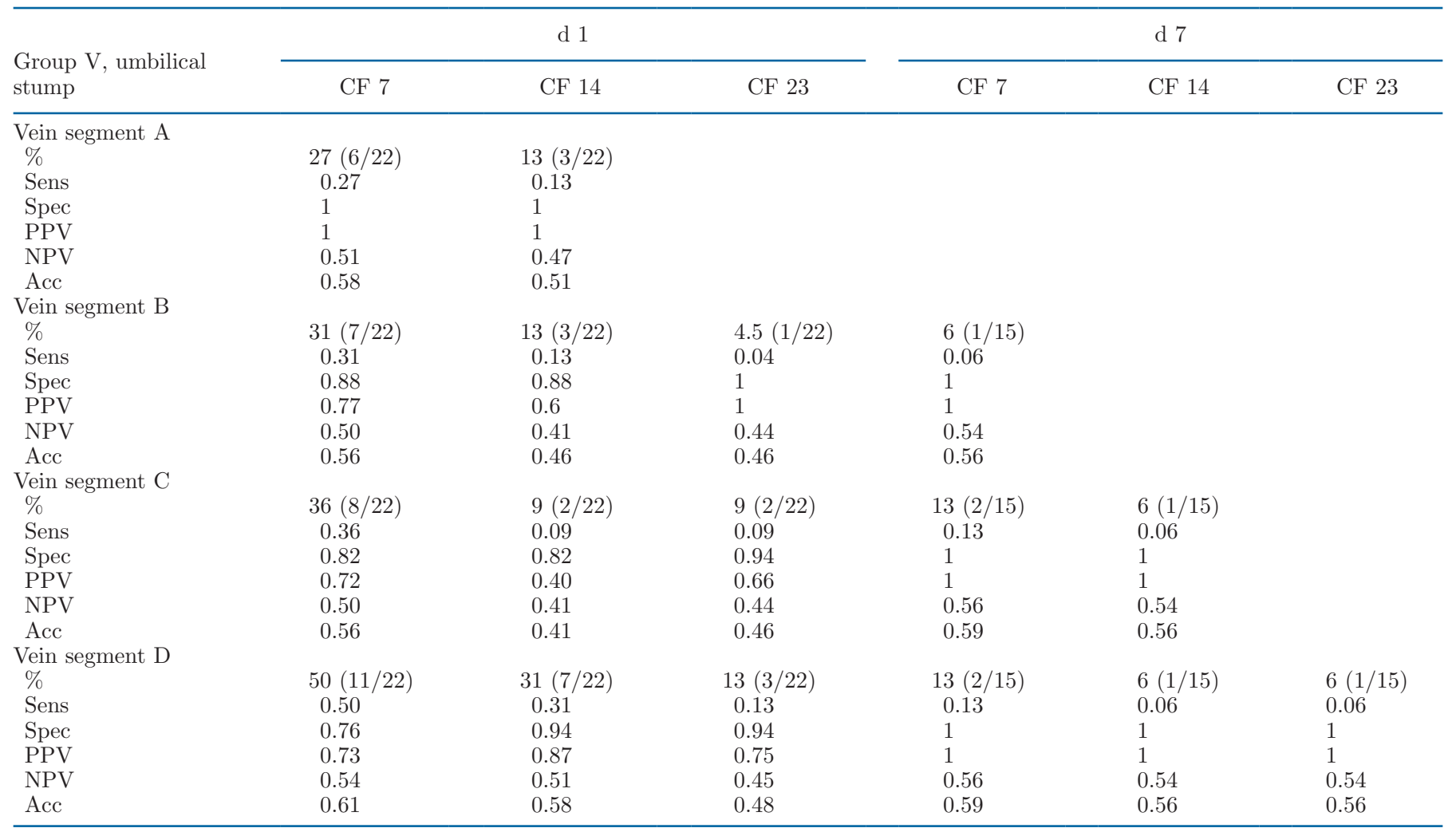

${ }^{1}$ Results are presented as percentages of positive color Doppler detection, followed parenthetically by number of calves positive at Doppler examination. Sens = sensitivity; $\mathrm{Spec}=$ specificity $\mathrm{PPV}=$ positive predictive value; NPV = negative predictive value; Acc $=$ accuracy. Vein $\mathrm{A}=$ umbilical vein immediately cranial to the inner umbilical ring; vein $\mathrm{B}=$ umbilical vein halfway between the abdominal wall and the liver; vein $\mathrm{C}$ $=$ umbilical vein near the liver; vein $\mathrm{D}=$ umbilical vein inside the liver. $\mathrm{CF} 7=$ color Doppler at $7 \mathrm{~cm} / \mathrm{s}$ velocity range. $\mathrm{CF} 14=\mathrm{color}$ Doppler at $14 \mathrm{~cm} / \mathrm{s}$ velocity range. $\mathrm{CF} 23=$ color Doppler at $23 \mathrm{~cm} / \mathrm{s}$ velocity range.

V). In these animals, similarly to the umbilical arteries and the umbilical stump, the umbilical vein showed a different pattern of involution, with an initial decrease of size followed by an increase of both mean diameter and area.

This irregular trend of regression in affected structures could be due to the localized protective inflammatory response, elicited by infectious agents, in the early stages of infection. As a response to tissue injury by pathogenic microorganisms, indeed, the body carries out physiologic changes to destroy, dilute, or wall off both the injurious agents and the injured tissue (Ackermann, 2017). The process begins with a transitory vasoconstriction, and is followed by a dilatation of the arterioles and the opening of new capillaries and venular beds in the area, with an increase in vascular permeability and exudation of fluids and plasma proteins from the vessels.

The inflammatory hemodynamic changes can also be responsible for the different results detected with color Doppler ultrasonography in the early days of exami- nation in our experimental study. Both frequency and percentage of speed-flow showed a significant difference between the 3 groups examined at the $\mathrm{d} 1$ and 7 ultrasound scan.

After birth in the healthy group (group H), blood flow was not detected in umbilical arteries at any time. Conversely, at d 1 in the group of calves affected by omphaloarteritis (group A), blood flow was detected at some velocity ranges (Figure 7). Particularly, at the $7 \mathrm{~cm} / \mathrm{s}$ velocity range blood flow was detected in $25 \%$ of calves in both arteries. At $14 \mathrm{~cm} / \mathrm{s}$, blood flow was detected in $20 \%$ of calves in the right artery and in $16 \%$ of calves in the left artery, and at $23 \mathrm{~cm} / \mathrm{s}$ in $12 \%$ of calves in the right artery and in $8 \%$ of calves in the left artery. However, after the d 1 examination, blood flow was never detected in umbilical arteries in healthy or affected calves. The findings of our study suggest that the detection of arterial blood flow in umbilical arteries within $24 \mathrm{~h}$ of birth using $7 \mathrm{~cm} / \mathrm{s}$ velocity range is more accurate than the other measurements of arterial blood flow in detection of the diseased calves. 
After birth (d 1) in healthy calves (group H), blood flow was not detected in segment A of the umbilical vein at any time at any velocity range, whereas in calves of group $\mathrm{V}$, blood flow was detected in 6 calves $(27 \%)$ at $7 \mathrm{~cm} / \mathrm{s}$ and in 3 of the 6 calves $(13 \%)$ at the $14 \mathrm{~cm} / \mathrm{s}$ velocity range.

At the d 1 ultrasound scan, in segment B, C, and D positive color Doppler was detected both in healthy and affected calves. Particularly, in group H, 2 calves had a positive flow detection in segment $\mathrm{B}$ and 3 calves in segment $\mathrm{C}$ of the vein, both at 7 and $14 \mathrm{~cm} / \mathrm{s}$ velocity range. In these calves, however, the ultrasonographic examination was performed only $2 \mathrm{~h}$ after birth, long before other scans. When the ultrasound was performed too early, the umbilical vein had no time to regress properly, and it was still possible to identify a flow. Furthermore, at d 1, a blood flow was detected in segment $D$ of the vein at the $7 \mathrm{~cm} / \mathrm{s}$ velocity range in 4 healthy calves. Three of them were the calves with a positive detection in segments $\mathrm{B}$ and $\mathrm{C}$ of the vein, and therefore, this result can be explained by a too early examination. Conversely, the other calf was scanned at a proper time. The positive detection in this case, however, could be due to the proximity of segment D of the umbilical vein with the left branch of the portal vein. Due to the large caliber and flow of
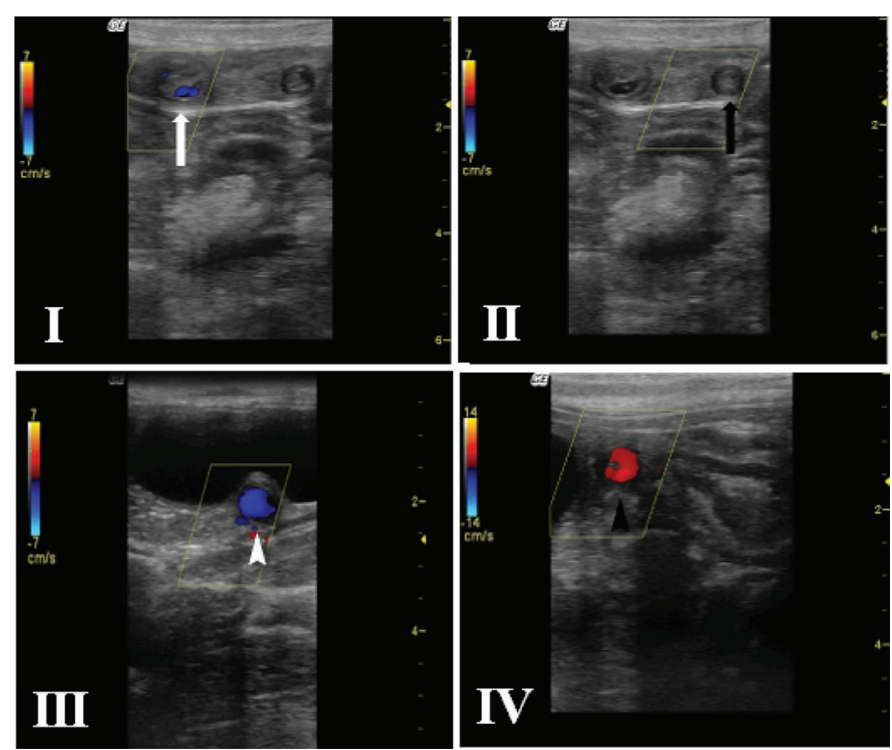

Figure 7. Color Doppler findings in the umbilical arteries in calves affected by omphaloarteritis (group A) at d 1. (I) Positive color Doppler flow, at $7 \mathrm{~cm} / \mathrm{s}$, on the right artery (white arrow); (II) negative color Doppler flow, at $7 \mathrm{~cm} / \mathrm{s}$, on the left artery (black arrow) of the same calf; (III) positive color Doppler flow, at $7 \mathrm{~cm} / \mathrm{s}$, on the left artery (white arrowhead); (IV) positive color Doppler flow, at $14 \mathrm{~cm} / \mathrm{s}$, on the left artery (black arrowhead).
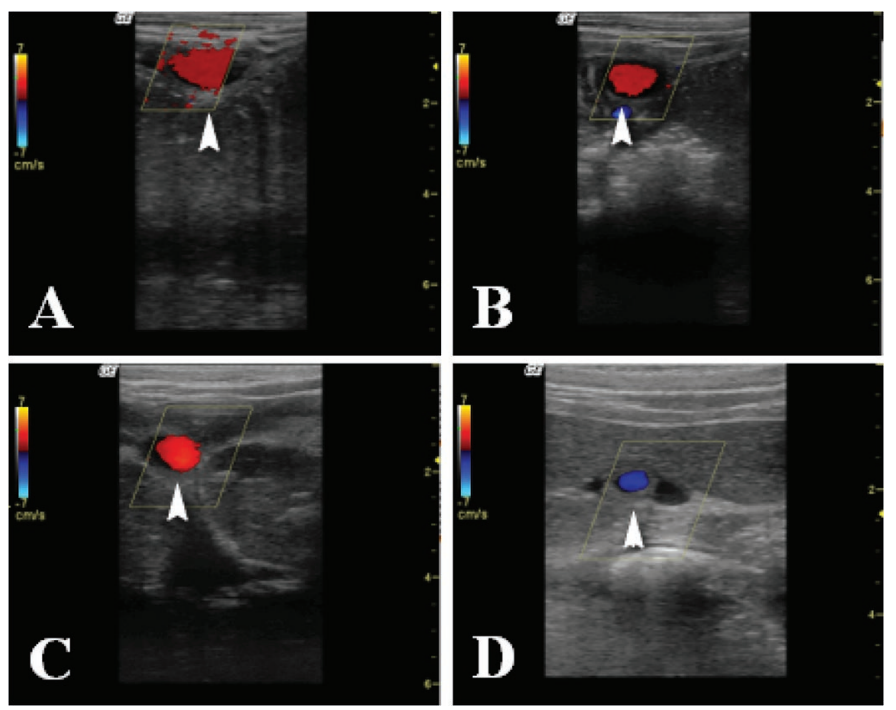

Figure 8. Positive color Doppler flow in the umbilical veins (arrowheads) in calves affected by omphalophlebitis (group V) at $\mathrm{d} 1$, at $7 \mathrm{~cm} / \mathrm{s}$. (A) umbilical vein in segment A; (B) umbilical vein in segment $\mathrm{B}$; (C) umbilical vein in segment $\mathrm{C}$; and (D) umbilical vein in segment D.

the portal vein, it may cause a regurgitation of blood into the umbilical vein, thus leading to an erroneous positivity to color Doppler examination. In the group of healthy calves (group H) blood flow at segment B, $\mathrm{C}$, and $\mathrm{D}$ of the umbilical vein was never detected after d 1 examination. In the group of calves affected by omphalophlebitis (group V), a positive color Doppler was detected both at $\mathrm{d} 1$ and 7 of examination. Particularly, at d 1, using a velocity range of $7 \mathrm{~cm} / \mathrm{s}$, blood flow was detected in $27,31,36$, and $50 \%$ of calves in segments A, B, C, and D, respectively (Figure 8). On d 7, using the $7 \mathrm{~cm} / \mathrm{s}$ velocity range, 1 calf had a positive color Doppler in vein B, 2 calves in vein $\mathrm{C}$ and $\mathrm{D}$, whereas at $14 \mathrm{~cm} / \mathrm{s} 1$ calf in segments $\mathrm{C}$ and $\mathrm{D}$, and at $23 \mathrm{~cm} / \mathrm{s}$ 1 calf in segment D. In the group of calves affected by omphalophlebitis, blood flow was not detected after d 7 examination, probably due to the presence of purulent material occluding the venous lumen. The findings of our study suggest that, for more accuracy, the color Doppler examination should be performed between $h$ 10 and 22 after birth at segment A of the umbilical vein, using $7 \mathrm{~cm} / \mathrm{s}$ velocity range. Furthermore, at d 7 , the detection of venous blood flow in umbilical vein using $7 \mathrm{~cm} / \mathrm{s}$ velocity range is accurate in detection of the diseased calves.

At the level of the umbilical stump, flow was not detected with any of the settings used in the study, in the healthy or affected group, at any time after birth. In both groups, after the $\mathrm{d} 7$ examination, blood flow was never detected in any segment of the umbilical arteries, 
umbilical stump, or umbilical vein at any of the velocity ranges used.

The color Doppler results showed a high reliability in the examination of the umbilical arteries and was slightly lower in the examination of the umbilical stump and the umbilical vein. Specificity was higher in the arteries than in the vein. In both arteries, at the $\mathrm{d} 1$ examination at the $7 \mathrm{~cm} / \mathrm{s}$ velocity range, specificity was $100 \%$, and in umbilical vein at segments A, B, C, and $\mathrm{D}$ it was $100,88,82$, and $76 \%$, respectively. The PPV was also higher in the arteries, with a value of $100 \%$, and lower in the vein, where it was 100, 77, 72, and $73 \%$ at segments A, B, C, and D, respectively. Sensitivity of color Doppler examination was low both in the arteries and in the vein, with slightly higher values in the vein. At the $\mathrm{d} 1$ examination at the $7 \mathrm{~cm} / \mathrm{s}$ velocity range, sensitivity was $25 \%$ in both arteries, whereas it was 27 , 31,36 , and $50 \%$, in the different segments of the vein.

\section{CONCLUSIONS}

Ultrasonography is an excellent method for the visualization of umbilical structures in calves and for the evaluation of their proper involution. Enlargement of these structures, coupled with an abnormal ultrasonographic appearance (i.e., presence of purulent hyperechoic material inside or nearby umbilical vessels), suggests an ongoing infection. The color Doppler imaging technique does not replace the standard ultrasonographic examination, but supplements it. It gives immediate information about the blood flow in umbilical vessels, indicating a localized protective inflammatory response in the early stages of infection. The most reliable results are those detected from umbilical arteries. Positive detection on color Doppler exam on the $\mathrm{d} 1$ scan, in our experimental study, is directly correlated with omphaloarteritis, with a $100 \%$ specificity and $100 \%$ PPV. However, the low sensitivity and, therefore, the high false negative rate suggest that the clinician should carefully evaluate each calf and reexamine those with suspected umbilical abnormalities on clinical examination or with ambiguous ultrasonographic appearance. Regarding the umbilical vein, furthermore, results should be more carefully evaluated. When the ultrasound is performed too early, the umbilical vein has not had time to regress properly, making it still possible to identify a flow inside it; these results can be confused with an inflammatory hemodynamic change in response to infection, although this is not the case. In our experimental study, the number of calves was adequate to perform a good statistical analysis. However, to obtain more reliable results, it would be necessary to increase the number of calves examined, and also consider other breeds of calves, to highlight any differences.

\section{ACKNOWLEDGMENTS}

The authors declare that they have no conflicts of interest.

\section{REFERENCES}

Ackermann, M. R. 2017. Inflammation and healing. Pages 73-131 in Pathologic Basis of Veterinary Disease - Expert Consult. 6th ed. J. F. Zachary, ed. Elsevier, St. Louis, MO.

Baxter, G. M. 1989. Umbilical masses in calves: Diagnosis, treatment, and complications. Compend. Contin. Educ. Vet. 11:505-513.

Bleul, U., B. Lejeune, S. Schwantag, and W. Kähn. 2007. Ultrasonic transit-time measurement of blood flow in the umbilical arteries and veins in the bovine fetus during stage II of labor. Theriogenology 67:1123-1133. https://doi.org/10.1016/j.theriogenology.2006 .12 .007 .

Bollwein, H., F. Weber, I. Woschée, and R. Stolla. 2004. Transrectal Doppler sonography of uterine and umbilical blood flow during pregnancy in mares. Theriogenology 61:499-509. https://doi.org/ 10.1016/s0093-691x(03)00225-5.

Bombardelli, J. A., C. H. Seino, G. A. Reis, C. L. Shecaira, M. R. Azedo, and F. J. Benesi. 2018. Aspectos ultrassonográficos dos components umbilicais de bezerros de raça Holandesa durante o processo de involução fisiológica. Arq. Bras. Med. Vet. Zootec. 70:382-390. https://doi.org/10.1590/1678-4162-9151.

Di Salvo, P., F. Bocci, R. Zelli, and A. Polisca. 2006. Doppler evaluation of maternal and fetal vessels during normal gestation in the bitch. Res. Vet. Sci. 81:382-388. https://doi.org/10.1016/j.rvsc .2006.03.004.

Lischer, C. J., and A. Steiner. 1993. Ultrasonography of the umbilicus in calves. Part 1: Ultrasonographic description of umbilical involution in clinically healthy calves. Schweiz. Arch. Tierheilkd. 135:221-230.

Lischer, C. J., and A. Steiner. 1994. Ultrasonography of the umbilicus in calves. Part 2: Ultrasonography, diagnosis and treatment of umbilical diseases. Schweiz. Arch. Tierheilkd. 136:227-241.

Mulon, P. Y., and A. Desrochers. 2005. Surgical abdomen of the calf. Vet. Clin. North Am. Food Anim. Pract. 21:101-132. https://doi .org/10.1016/j.cvfa.2004.12.004.

O'Brien, R. T., and L. J. Forrest. 1996. A retrospective study of umbilical sonography in calves. Vet. Radiol. Ultrasound 37:63-67. https: //doi.org/10.1111/j.1740-8261.1996.tb00815.x.

Rings, D. M. 1995. Umbilical hernias, umbilical abscesses, and urachal fistulas-surgical considerations. Vet. Clin. North Am. Food Anim. Pract. 11:137-148. https://doi.org/10.1016/s0749-0720(15)30512 -0 .

Sinkovskaya, E., A. Klassen, and A. Abuhamad. 2013. A novel systematic approach to the evaluation of the fetal venous system. Semin. Fetal Neonatal Med. 18:269-278. https://doi.org/10.1016/ j.siny.2013.05.009.

Staller, G. S., E. P. Tulleners, V. B. Reef, and P. A. Spencer. 1995. Concordance of ultrasonographic and physical findings in cattle with an umbilical mass or suspected to have infection of the umbilical cord remnants: 32 cases (1987-1989). J. Am. Vet. Med. Assoc. 206:77-82.

Steiner, A., and B. Lejeune. 2009. Ultrasonographic assessment of umbilical disorders. Vet. Clin. North Am. Food Anim. Pract. 25:781794. https://doi.org/10.1016/j.cvfa.2009.07.012.

Virtala, A. M., G. D. Mechor, Y. T. Gröhn, and H. N. Erb. 1996a. Morbidity from nonrespiratory diseases and mortality in dairy heifers during the first three months of life. J. Am. Vet. Med. Assoc. 208:2043-2046. 
Virtala, A. M., G. D. Mechor, Y. T. Gröhn, and H. N. Erb. 1996b. The effect of calfhood diseases on growth of female dairy calves during the first three months of life in New York State. J. Dairy Sci. 79:1040-1049. https://doi.org/10.3168/jds.S0022-0302(96)76457 $-3$.

Waldvogel, D., and U. Bleul. 2014. Effect of xylazine, isoxsuprine, and lidocaine on Doppler sonographic uterine and umbilical blood flow measurements in cows during the last month of pregnancy. Theriogenology 81:993-1003. https://doi.org/10.1016/j.theriogenology 2014.01.031.

Watson, E., M. B. Mahaffey, W. Crowell, B. A. Selcer, D. D. Morris, and L. Seginak. 1994. Ultrasonography of the umbilical structures in clinically normal calves. Am. J. Vet. Res. 55:773-780.

Williams, H. J., A. V. Gillespie, J. W. Oultram, P. J. Cripps, and A. N. Holman. 2014. Outcome of surgical treatment for umbilical swellings in bovine youngstock. Vet. Rec. 174:221-224. https://doi .org/10.1136/vr.101736.

\section{ORCIDS}

G. Guerri ๑ https://orcid.org/0000-0002-3110-107X

M. Vignoli (® https://orcid.org/0000-0002-4981-4051

C. Palombi ๑ https://orcid.org/0000-0002-6811-0199

M. Monaci $\odot$ https://orcid.org/0000-0002-6506-6794

L. Petrizzi @ https://orcid.org/0000-0001-7830-7545 